\title{
PENGEMBANGAN INOVASI PEMBUATAN BATU BATA DARI LIMBAH PLASTIK DAN ABU SEKAM PADI SEBAGAI UPAYA MENGURANGI PENCEMARAN LINGKUNGAN
}

\author{
Mitha Vania Simamora \\ Erviana Bulan Nasution \\ Moch Javi Nindika \\ Henny Zurika Lubis \\ Fakultas Ekonomi Dan Bisnis Universitas Muhammadiyah Sumatera Utara \\ Jln. Kapten Muchtar Basri No. 3 Medan 20238 \\ mithajilwww@gmail.com
}

\begin{abstract}
ABSTRAK
BABALIAD adalah sebuah usaha yang bergerak di bidang produksi dan distribusi bahan bangunan dengan spesialisnya dibidang batu bata yang berasal dari recycle sampah plastik dan abu sekam padi, dengan memproduksi dan menjual batu bata yang berasal dari bahan daur ulang. Produk BABALIAD yang di produksi berupa produk seperti batu bata bentuk biasa, batu bata bentuk oval, batu bata berlubang, batu bata berbentuk balok, batu bata custom, sebagai hiasan didalam maupun diluar rumah, dan batu bata yang diproduksi juga bermacam-macam sesuai selera pelanggan. Produk ini menggunakan bahan limbah sampah plastik dan memanfaatkan abu sekam padi. BABALIAD memiliki keunikan tersendiri sehingga ada nilai lebih dari BABALIAD ini dibanding dengan produk batu bata lainnya, karena dari segi pembuatannya berasal dari limbah daur ulang.
\end{abstract}

Kata kunci : Inovasi batu bata, limbah plastik, abu sekam padi

\begin{abstract}
BABALIAD is a business that is engaged in the production and distribution of building materials with its specialists in the field of bricks originating from recycling plastic waste and rice husk ash, by producing and selling bricks from recycled materials. BABALIAD products are manufactured in the form of products such as ordinary bricks, oval-shaped bricks, hollow bricks, beam-shaped bricks, custom bricks, as decorations inside and outside the house, and the bricks produced also vary according to customer tastes. This product uses plastic waste material and utilizes rice husk ash. BABALIAD has its own uniqueness so that there is more value than BABALIAD compared to other brick products, because in terms of manufacturing it comes from recycled waste.
\end{abstract}

Keywords: Innovation of bricks, plastic waste, rice husk ash 
Liabilities Jurnal Pendidikan Akuntansi

e-ISSN 2620-5866

Volume 2. No.2 Agustus 2019 (109-114)

Doi. 10.30596/liabilities.v2i2.3249

\section{PENDAHULUAN}

Pada masa sekarang, industri batu bata banyak kita jumpai di berbagai wilayah di Indonesia, baik dikota atau pun didesa. Sudah banyak produsen/penghasil batu bata, dimana ini merupakan suatu kompetitor kami dalam memproduksi batu bata. Batu bata yang banyak dijual dipasaran adalah bentuk batu bata biasa, dimana bentuk batu bata biasa hanya terkhusus untuk pembuatan bangunan saja. Masyarakat yang ada di Indonesia lebih mengenal atau lebih banyak mengetahui tentang batu bata biasa, ini merupakan salah satu bentuk kerja keras kami untuk lebih mengenal kan produk kami kemasyarakat luas. Tapi, produksi batu bata yang kami buat bukan untuk pembuatan bahan bangunan, produksi batau bata kami sendiri lebih terkhusu untuk hiasan dan pembuatan kolomkolam mini. Produksi batu bata kami memiliki berbagai bentuk varian sesusai dengan selera pelanggan. Dan kami juga memproduksi batu bata yang memiliki warna menarik untuk dijadikan hiasan. Selain dijadikan hiasan, produk batu bata kami juga bisa digunakan untuk pembuatan kolam-kolam mini, karena memiliki keunggulan yang berbeda dengan batu bata lainnya. Keunggulan yang dimiliki babaliad kami adalah ramah lingkungan, tidak berlumut, ringan, dan tahan air. Batu bata yang kami hasilkan berasal dari recycle sampah plastik dan abu sekam padi, dengan memproduksi dan menjual batu bata yang berasal dari bahan daur ulang. Produk ini menggunakan bahan limbah sampah plastik dan memanfaatkan abu sekam padi. Tujuan dari produk ini adalah untuk memperkenalkan kepada masyarakat bahwa batu bata tidak hanya dijadikan sebagai bahan pembuatan bangunan saja, tapi bisa digunakan untuk hiasan untuk mempercantik interior ruangan, sera sebagai bahan dasar untuk pembuatan kolam-kolam mini karena bata kami tidak mudah berlumut.

\section{METODE}

Teknik yang digunakan dalam penelitian ini adalah analisis kualitatif dengan cara mendeskripsikan atau menggambarkan keadaan objek penelitian yang sesungguhnya untuk mengetahui pelaksanaan kegiatan produksi babaliad

\section{HASIL DAN PEMBAHASAN}

Teknik Pembuatan Komoditas Usaha

Tahapan produksi yang harus dilalui dalam 
pembuatan Babaliad dapat di dilihat dalam alur berikut, yaitu:

1. Siapkan alat dan bahan.

2. Siapkan plastik atau tempattempat yang berbahan dasar plastik.

3. Hidupkan api yang cukup besar terlebih dahulu.

4. Masukkan oli kedalam kuali dan campurkan plastik kedalamnya.

5. Aduk rata kedua bahan tersebut dengan perbandingan 70\% limbah sampah plastik dan $30 \%$ sekam padi. Kemudian, aduk rata campuran oli dan plastik sampai benar benar larut, setelah bahan dasar tadi tercampur rata, lalu masukkan abu sekam padi sesuai takaran dan menghasilkan bentuk yang merata dan padat.

6. Setelah

bahan sudah tercampur, langkah selanjutnya yaitu, memasukkannya kedalam cetakan batu bata yang bentuknya bervariasi.

7. Agar batu bata bisa bertahan lama kita bisa melakukan proses pengeringan dengan cara menyusun batu bata dan mengeringkannya dibawah terik sinar matahari kurang lebih sekitar 2-3 jam, tujuannya agar batu bata dapat bertahan lama dan mempercepat suhu yang ada didalam susunan batu bata cepat naik keatas.

8. Setelah proses pembuatan dan pengeringan, kemudian barulah batu bata siap dijual.

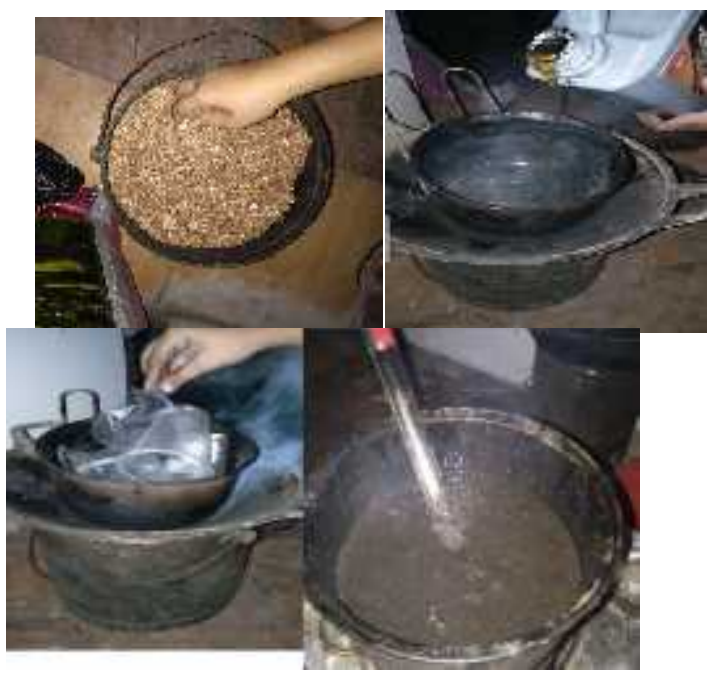

Gambar 1. Proses pembuatan babaliad

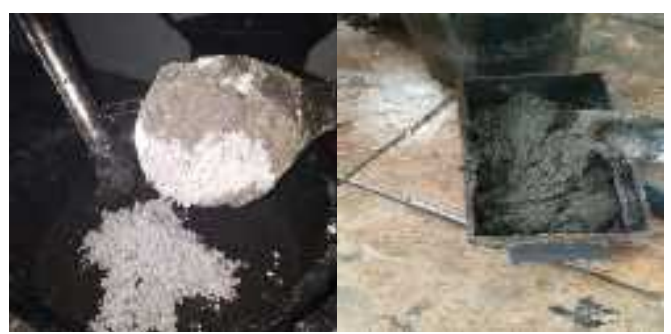


Volume 2. No.2 Agustus 2019 (109-114)

Doi. 10.30596/liabilities.v2i2.3249
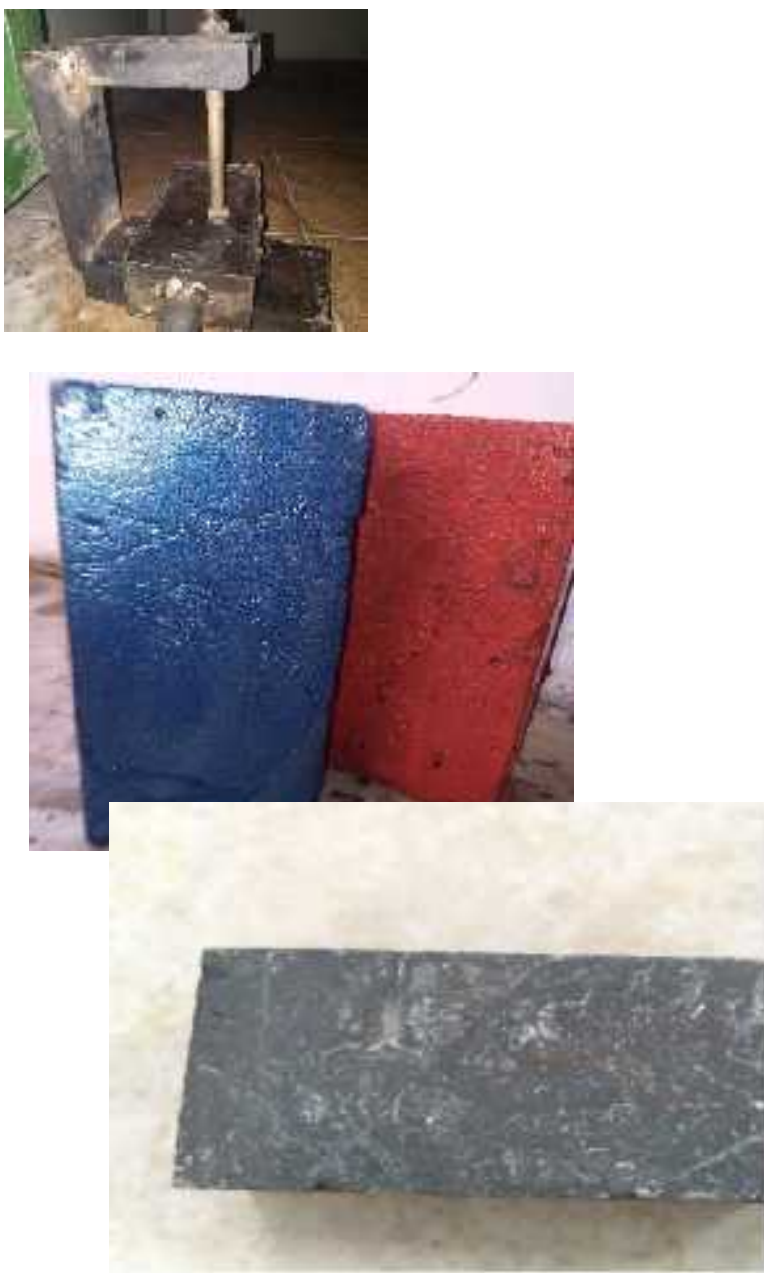

babaliad

\section{Strategi Pemasaran}

Strategi pemasaran yang kami terapkan adalah menjualnya kepada masyarakat langsung dan menjualnya melalui media sosial meliputi: WhatsApp (082363067447 / 085261570704$)$ Instagram @MJEBABALIAD_inovasi batu bata Facebook MJE BABALIAD, Twitter@MJEBABALIAD

PENJUALAN MJE BABALIAD :

BEP (unit)

$$
\begin{aligned}
& \frac{I}{p-V}=\mathrm{fc}=\mathrm{Rp} \cdot 200.000 \\
& \mathrm{Vc}=\mathrm{Rp} .150 .000 / 100 \\
& \mathrm{P} \quad=\text { Rp. } 10.000 \\
& =\frac{k .2 \quad .0}{R \cdot 1.0-1.5}=\frac{k .2 \quad .0}{R .8 .5}=23 \text { unit } \\
& \mathrm{BEP} \text { (rupiah) } \frac{I}{1-\frac{v}{p}} \\
& =\frac{K .2 \quad .0}{1-\frac{R .1 .5}{R .1 .0}}=\frac{K .2 \quad .0}{0.8}=\text { Rp. } 235.294
\end{aligned}
$$

\section{Analisis Keuangan:}

Produksi

$\mathrm{P} \quad=$ Rp. 10.000

$\mathrm{FC}=$ Rp. 200.000

$\mathrm{Vc}=\mathrm{Rp} \cdot 7.710 .000$

Jumlah total produksi $=1000$ unit

Biaya produksi

= biaya tetap + biaya tidak tetap

$=$ Rp. $200.000+7.710 .000$

$=$ Rp. 7.910 .000

Biaya pokok penjualan

= biaya produksi : jumlah produksi

$=$ Rp. $7.910 .000: 1000$ unit

$=$ Rp. 7.910 
Hasil usaha

$=$ jumlah produksi $\mathrm{x}$ harga

$=1000 \times 10.000$

$=$ Rp. 10.000 .000

Keuntungan

= hasil usaha - biaya produksi

$=$ Rp. 10.000.000 -Rp. 7.910.000

$=$ Rp. 2.090 .000

$$
\begin{aligned}
\mathrm{R} / \mathrm{C} & =\text { hasil usaha }: \text { biaya produksi } \\
& =\mathrm{Rp} .10 .000 .000: \mathrm{Rp} .7910 .000 \\
& =1,26
\end{aligned}
$$

Artinya, usaha ini layak untuk

dijalankan. Dengan melihat keuntungan

jika nilai $\mathrm{R} / \mathrm{C}$ semakin tinggi maka

tingkat keuntungan semakin tinggi

Penjualan produk MJE BABALIAD sangat diterima baik oleh masyarakat pada bulan juni.

Berikut Tabel 1. Penjualan MJE

$$
\text { BABALIAD }
$$

\begin{tabular}{|c|c|c|}
\hline Tanggal & Terjual & Keterangan \\
\hline \hline 2 juni 2019 & 25 & Tercapai \\
\hline 12 juni 2019 & 26 & tercapai \\
\hline 24 juni 2019 & 30 & tercapai \\
\hline TOTAL & 80 & Tercapai \\
\hline
\end{tabular}

\section{POTENSI HASIL}

Kami akan terus menjual secara langsung kepada masyarakat dan akan membuat komoditas pembuatan babaliad. Selain itu, untuk menjaga agar produk ini mempunyai kekuatan hukum kami sudah mendaftar untuk hak merek produk kami dan masih dalam proses pengurusan berkas dengan dibantu oleh Badan Bantuan Hukum UMSU

Manfaat terhadap aspek sosial ekonomi dari program ini adalah sebagai berikut :

a. Aspek sosial

Terciptanya lapangan pekerjaan sehingga dapat membantu mengurangi angka pengangguran.

b. Aspek program usaha membantu memperkuat hubungan kerjasama antar produksi batu bata biasa dan pemilik usaha toko-toko alat bangunan.

c. Aspek ekonomi Memberi profit yang sangat besar bagi pemilik usaha dan dapat menciptakan satu unit bisnis bidang produksi.

\section{RENCANA TAHAPAN BERIKUTNYA}

Setelah melakukan evaluasi usaha untuk mengembangkan produk MJE BABALIAD ini lebih berkembang lagi maka rencana selanjutnya yang dilakukan adalah:

1. Memperluas penjualan

2. Menambah jenis batu bata sesuai minat pelanggan 
Liabilities Jurnal Pendidikan Akuntansi

e-ISSN 2620-5866

Volume 2. No.2 Agustus 2019 (109-114)

Doi. 10.30596/liabilities.v2i2.3249

3. Mengurus hak merek produk

4. Membentuk kelompok pembuatan produk batu bata

5. Membuka toko produksi MJE BABALIAD

\section{KESIMPULAN}

Batu bata yang kami hasilkan berasal dari recycle sampah plastik dan abu sekam padi, dengan memproduksi dan menjual batu bata yang berasal dari bahan daur ulang. Produk ini menggunakan bahan limbah sampah plastik dan memanfaatkan abu sekam padi.

Tujuan dari produk ini adalah untuk memperkenalkan kepada masyarakat bahwa batu bata tidak hanya dijadikan sebagai bahn pembuatan bangunan saja, tapi bisa digunakan untuk huiasan untuk mempercantik interior ruangan.

Dan sebagai bahan dasar untuk pembuatan kolam-kolam mini karena bata kami tidak mudah berlumut.

\section{DAFTAR PUSTAKA}

Juhana (2009): Pemanfaatan Sampah Plastik Sebagai Bahan Bangunan Alternatif di Kota Makassar, hasil penelitian hibah dosen muda Dikti.

https://www.kompasiana.com/bamset2014/ 5719db2f8123bd150829951f/mengolah-

$\underline{\text { limbah-plastik-jadi-batu-bata-ala-siswa-sd }}$

https://properti.kompas.com/read/2016/08/12 /070000121/Inovasi.Baru.Sampah.Plastik.Bis a.Jadi.Dinding.Rumah 